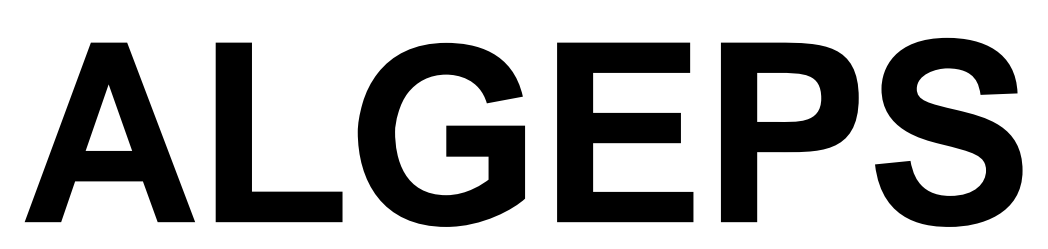

REVISTA DE GEOLOGIA, SÈRIE B no 626 - Abril del 2013

ISSN $1132-7014$

D.L.B. 28.178 - 92

16 pàgines

\begin{abstract}
RECORREGUT GEOLÒGIC I MINERALÒGIC PER LA COMARCA DE LA TERRA ALTA: DES DE PRAT DE COMPTE A HORTA DE SANT

JOAN
\end{abstract}

Josep M. Mata-Perelló i Joaquim Sanz Balagué 


\title{
RECORREGUT GEOLÒGIC I MINERALÒGIC PER LA COMARCA DE LA TERRA ALTA: DES DE PRAT DE COMPTE A HORTA DE SANT JOAN
}

\author{
Per Josep M. MATA-PERELLÓ i Joaquim SANZ BALAGUÉ
}

\section{ADVERTIMENTS PREVIS}

Com en altres recorreguts de RECERCA GEOLÒGICA I MINERALÒGICA ..., si es disposa del temps suficient, poden efectuar-se passant per totes les parades i filloles. En cas contrari, recomanem prescindir de les anomenades PARADES - CONDICIONALS.

També recomanem de cercar la informació més adient, sobre els trams a recórrer mitjançant camins de terra, o de pista. Precisament, en aquest itinerari, hi ha alguns trajectes d'aproximació cap a les mines, que haurem de fer per camins de terra en irregular estat de conservació.

Per d'altra banda, recomanem tenir una cura extrema de la NATURA, evitant qualsevol forma d'agressió sobre ella, o de fer-n'hi un mal ús del que en ofereix la nostra mare Terra.

\section{BREU INTRODUCCIÓ}

En aquesta ocasió, el recorregut del present itinerari discorrerà per una zona en la qual conflueixen tres unitats geològiques netament diferenciades: la Depressió Geològica de l'Ebre, la Serralada Prelitoral Catalana (del Sistema Mediterrani, com l'anterior), i la Serralada Ibèrica, tot i que en realitat es circularà quasi sempre per la denominada Zona d'Enllaç entre el Sistema Mediterrani i la Serralada Ibèrica.

Tot i això, en aquest curt recorregut es circularà sempre per segon sector, entre Prat de Compte i Horta de Sant Joan. Per d'altra banda, cal fer esment de que als trams finals del recorregut, també es circularà per la Depressió Geològica de l'Ebre, com succeirà pels voltant d'Horta de Sant Joan.

Finalment, cal dir, que el recorregut de l'itinerari, discorrerà per una sola de les comarques, de la Regió de Tortosa; concretament per la de la Terra Alta. 


\section{OBJECTIUS FONAMENTALS D’AQUEST ITINERARI}

Els objectius fonamentals que es pretenen aconseguir en aquest itinerari, es poden concretar en els següents aspectes generals:

1.- Observació i descripció dels materials terciaris (de l'Eocè i de l'Oligocè) de la Depressió Geològica de l'Ebre, que pertanyen majoritàriament al complex al-luvial de Gandesa - Horta de Sant Joan. Aquests materials, els veurem cap a la fi del recorregut, per les immediacions d’Horta de Sant Joan.

2.- Observació i descripció dels materials mesozoics (del Triàsic, del Juràssic i del Cretàcic) i dels cenozoics (de l'Eocè i de l'Oligocè), que constitueixen la Serralada Prelitoral Catalana. Aquests materials els trobarem a diferents indrets del recorregut.

3.- Observació de les estructures locals d'aquestes unitats geològiques acabades d'esmentar, que trobarem al llarg del recorregut de l'itinerari, i de les relacions existents entre elles. Així, ens referirem a les següents:

3A) a l'estructura de Branca Externa de la Serralada Prelitoral Catalana (integrant del Sistema Mediterrani), que trobarem a diferents trams del recorregut. En molts indrets, aquests es troben prop de la seva Zona d'Enllaç amb el Sistema Ibèric.

3B) de l'estructura de la Depressió Geològica de l'Ebre, que veurem als darrers trams del recorregut.

3C) de les relacions existents entre les unitats i sotsunitats geològiques acabades d'esmentar.

4.- Observació i reconeixement de diferents mineralitzacions situades a diferents indrets del recorregut de 1'itinerari, (però sempre dintre de la Serralada Prelitoral Catalana), com són les relacionades amb les formacions argiloses, que trobarem a diversos indrets dels termes de Prat de Compte i d'Horta de Sant Joan, ubicades entre els materials del trànsit del Cretàcic Superior al Paleocè.

5.- Observació de les antigues explotacions mineres relacionades amb les mineralitzacions anteriors. Al respecte, cal dir que totes elles es troben actualment aturades.

6.- Observació i anàlisi dels impactes produïts sobre el Medi Natural (i sobre el Medi Ambient), tant per les explotacions mineres anteriors, com per altres activitats humanes.

7.- Observació dels diferents indrets relacionats amb el Patrimoni Geològic i Miner, que trobarem al llarg del recorregut. Entre aquests indrets, cal fer esment, de les Roques de Benet, situades prop de la població d’Horta de Sant Joan.

\section{ANTECEDENTS BIBLIOGRÀFICS}

Pel que fa al recorregut del present itinerari, existeixen alguns antecedents molt propers, obra del mateix autor del present itinerari. Es tracta de MATA-PERELLÓ (1996b, 1997, 2000a, 2000b, 2001a, 2001b i 2005). Un altre antecedent parcial, obra del mateix 
autor, es troba a MATA-PERELLÓ (1989), i correspon a un altre itinerari. Tanmateix, cal fer esment del treball de MATA-PERELLÓ i MONTANÉ GARCÍA (2006), en un itinerari fora semblant al present. També cal fer esment del treball de MATA - PERELLÓ et altri (2006).

Pel que fa a la descripció de les mineralitzacions d’aquesta comarca, farem esment d'un altre treball del mateix autor, de MATA-PERELLÓ (1991), relatiu a les mineralitzacions catalanes en general. Uns altres antecedents, cal situar-los en MATAPERELLÓ (1995a i 1995b), relatius als inventaris mineralògics de les comarques de la Terra Alta i del Matarranya.

I, finalment, pel que fa a l'estructura geològica de la zona per la qual discorre l'itinerari, farem esment dels treballs de GUIMERÀ et altri (1982) i de RIBA et altri (1976). També, i dintre d'aquest apartat, també farem esment de diversos treballs de l'IGME (1972). Tots ells són relatius a diversos fulls geològics corresponents als indrets per on passarà el recorregut de l'itinerari.

Tots aquests treballs referenciats, i d'altres, figuren esmentats per ordre alfabètic a l'apartat dedicat a la BIBLIOGRAFIA.

\section{RECORREGUT DE L'ITINERARI}

El recorregut de 1'itinerari començarà dintre de la comarca de la Terra Alta, concretament a Prat de Comte, per on es faran diverses aturades. A continuació, el recorregut es dirigirà cap a les immediacions de la població d'Horta de Sant Joan, per on s'efectuaran noves aturades. En una d'aquestes, es farà una fillola, per tal d'arribar a l'interessant paratge de les Roques de Benet. Després de retornar al darrer poble esmentat, finalitzarà el recorregut.

\section{DESCRIPCIÓ DE L'ITINERARI}

Com de costum, estructurarem el recorregut de l'itinerari en una sèrie de PARADES, que tot seguit anirem veient. En cada una d'aquestes aturades farem un breu comentari (geològic o mineralògic, segons s'escaigui).

Cada una d'aquestes parades tindrà un número, i un topònim representatiu. Per d'altra banda, s'indicarà el nom del poble més proper, el municipi al qual pertany l'indret, $\mathrm{i}$ la comarca on es troba situat. Per d'altra banda, també indicarem en cada cas, i entre parèntesi, el full topogràfic on es troba l'aturada.

Finalment, cal dir que el recorregut de l'itinerari s'inclourà dintre dels següents fulls, del "Mapa Topográfico Nacional", realitzats a l'escala 1:50.000 per 1'"Instituto Geográfico y Catastral": 470 (dit de Gandesa) i 496 (dit d'Horta de Sant Joan).

Així doncs, la relació de parades ordenades, que composen aquest itinerari geològic i mineralògic, és el següent: 


\section{PARADA 1. EXPLOTACIONS LUTÍTIQUES DE PRAT DE COMPTE, (terme municipal de Prat de Compte, comarca de la Terra Alta). (Full 496).}

El recorregut de l'itinerari s'iniciarà al poble de Prat de Compte. Més endavant, ens caldrà anar directament a les explotacions lutítiques del Barranc de la Xalamera, on farem la primera aturada després de recórrer poc menys de 1'5 Km des del poble.

En aquest recorregut, hem tornat a tallar la sèrie, tot i que sovint hem transitat per prop del contacte Cretàcic-Paleocè. Així, sovint hem tallat afloraments dels materials mesozoics (del Triàsic, Juràssic i Cretàcic), així com dels cenozoics (del Burdigalià). Tots ells formen part de la Serralada Prelitoral Catalana.

En aquest lloc hi ha una explotació d'uns nivells lutítics, que pertanyen al trànsit del Cretàcic Superior a l'Eocè. Aquests materials pertanyen a la Serralada Prelitoral Catalana del Sistema Mediterrani, on ens trobem ara situats.

Entre aquests nivells, que aquí són molt sorrencs, es troba una abundant presència d'HEMATITES, i naturalment de CAOLINITA, que és el mineral explotat. També cal fer esment de la presència de QUARS (en forma d'arena).

Cal dir, per d'altra banda, que a més a més d'aquesta explotació de materials refractaris, n'existeixen d'altres, situades a diferents indrets del terme de Prat de Compte, i ubicades sempre entre aquests mateixos materials.

PARADA 2 - CONDICIONAL. CARRETERA CAP A HORTA DE SANT JOAN, IMMEDIACIONS DE LA VENTA DEL CAIXARRO, (terme municipal d'Horta de Sant Joan, comarca de la Terra Alta). (Full 496).

Des de la parada anterior, cal continuar per la carretera T-330, anant cap a ponent, cap a Horta de Sant Joan, en arribar a les immediacions de la Venta del Caixarro, a uns $3 \mathrm{Km}$ de l'anterior, caldrà fer-n hi una altra.

En aquest recorregut entre Prat de Compte i l'indret on ara som, hem anat trobant els materials esmentats a la parada anterior. Molt sovint els trobem verticalitzats, prop del seu contacte amb els trams detrítics de la Formació Montsant, els quals s'ubiquen dintre de la Depressió Geològica de 1’Ebre.

Precisament, des d'aquest indret, i mirant cap a ponent, cap al Turó de Santa Bàrbara, es pot veure molt clar com aquests materials verticalitzats pas perdent inclinació, tornant-se cada cop més subhoritzontals, descrivint així una interessant discordança progressiva de la que parlarem a les properes aturades.

PARADA 3 - CONDICIONAL. PARTIDA DE SOLANS, (terme municipal d'Horta de Sant Joan, comarca de la Terra Alta). (Full 496).

Des de la parada anterior, cal anar cap a Horta de Sant Joan, per la carretera T330. En arribar al trencall que va cap a la població (la carretera T-334) caldrà anar-hi, 
per tal de fer una fillola $i$ una aturada a l'indret de la Partida Solans. Aquest indret es troba a uns $2 \mathrm{Km}$ del poble, $i$ ans 12 de la parada anterior.

En el recorregut entre la parada anterior i Horta de Sant Joan hem continuat trobant els materials esmentats anteriorment a les parades anteriors. Així, prop de la carretera hem seguit veient els materials verticalitzats, de la Formació Montsant, els quals s'ubiquen dintre de la Depressió Geològica de 1’Ebre.

Per d'altra banda, en el recorregut, des del trencall d'Horta de Sant Joan s'han anat tallant els nivells lutítics $i$ gresencs de la Formació Flix (la qual forma aquí part del Complex al·luvial de Gandesa - Horta de Sant Joan).

A l'indret de la parada, $i$ molt a prop de la carretera, es poden trobar interessants mostres de GUIX FIBRÓS (amb gruixos de 10-15cm). Aquests guixos són sempre secundaris $i$ es troben entre els nivells de la Formació Flix. El guix es troba reblint diàclasis, i plans d'estratificació alhora.

Des d'aquest indret, es poden observar, mirant cap al Nord ( $i N N W)$, uns interessants paleocanals, desenvolupats entre els materials de la ja reiteradament esmentada Formació Flix. Cal dir que tots aquests materials, es troben inclinats amb una clara verònica septentrional. Es de destacar que aquests paleocanals són més abundants cap al SE que cap al NW, pel fet de trobar-se prop de la zona més detrítica, on aflora amplament la Formació Montsant.

Per d'altra banda, a molt poca distància d'aquest lloc (a uns 100m), i continuant a peu pel camí, tot mirant cap a llevant, es pot veure una interessant discordança progressiva entre els materials de la Formació Montsant, que alhora es troben en contacte discordant amb els nivells calcaris de la Serralada Prelitoral Catalana.

\section{PARADA 4. BARRANC DEL SALT, ROQUES DE BENET, (terme municipal d’Horta de Sant Joan, comarca de la Terra Alta). (Full 496).}

Des de la parada anterior, cal sobrepassar el poble, per a continuar després cap a la cruilla amb la carretera que, procedent de Prat de Compte, es dirigeix cap a Vall-de-roures. Des de la cruïlla, cal seguir per la carretera que va als Estrets, fins arribar al peu de les Roques de Benet, on caldrà fer la present parada, després d'un recorregut proper als $8 \mathrm{Km}$ des de la parada anterior.

En aquest recorregut, des d'Horta de Sant Joan, s'han continuat tallant els materials terciaris, que tornen a ésser majoritàriament de la Formació Flix. Més endavant s' ha passat a la Serralada Prelitoral Catalana, que aquí es troba encavalcant als anteriors materials, fet que no succeeix en altres indrets propers.

Els materials que constitueixen aquesta serralada són eminentment calcaris, i pertanyen al Juràssic i al Cretàcic. També cal dir que aquest sector de la serralada forma part de la Zona d'Enllaç amb el Sistema Ibèric.

Per sobre d'aquests materials mesozoics acabats d'esmentar, es troben uns interessants afloraments dels nivells detrítics dels trams superiors de la Formació Montsant 
(que com ja s'ha dit, aquí forma part del Complex al-luvial de Gandesa-Horta de Sant Joan).

Aquests materials són lleugerament posttectònics, tot i que es troben lleugerament deformats per des darreres convulsions. FOTOGRAFIA 1

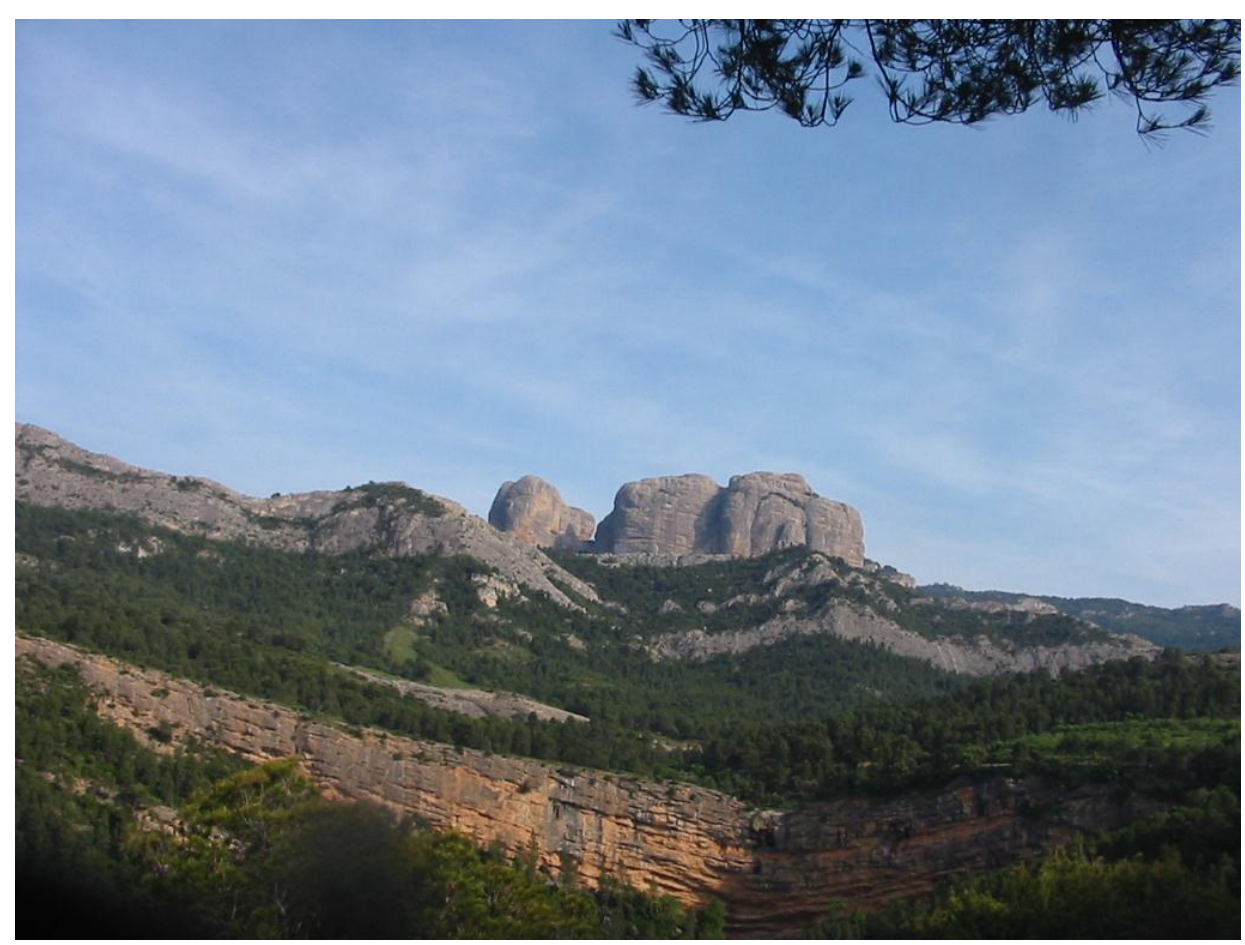

FOTOGRAFIA 1

Les Roques de Benet

A la part superior afloren nivells de conglomerats postorogènics.

A la part inferior hi ha un aflorament dels materials carbonatats mesozoics

\section{EN AQUEST INDRET FINALITZA EL RECORREGUT DE}

\section{REFERÈNCIES BIBLIOGRÀFIQUES}

GUIMERÀ, J. et altri (1992).- Geologia (II), Història Natural dels Països Catalans, Vol.2, 547 pag. Enciclopèdia Catalana, S.A. Barcelona

IGME (1974).- Mapa Geológico de España a escala 1:200.000. Sintesis de la Cartografia existente. Hoja y memória no 41 (Tortosa). Inst. Geol. Min. España. Minist. Indústria. Madrid 
MATA-PERELLÓ, J.M. (1989).- Una recerca mineralògica per les terres de 1'Ebre: del Matarranya al Priorat. But. Col. Ofi, de Doctors i Llicenciats, n 67, 15pag. Barcelona

MATA-PERELLÓ, J.M. (1991).- Els Minerals de Catalunya. Arxius de la Secció de Ciències, t. XCIII, 442 pag. Institut d'Estudis Catalans. Barcelona

MATA-PERELLÓ, J.M. (1995a).- Inventari Mineralògic de la comarca de la Ribera d’Ebre, Terra Endins, n 9, 23 pag. Manresa

MATA-PERELLÓ, J.M. (1995b).- Inventari Mineralògic de la comarca de la Terra Alta, Terra Endins, n 10,22 pag. Manresa

MATA-PERELLÓ, J.M. (1996).- Itinerari geològic i mineralògic entre Gandesa, la Fontcalda i Vall-de -roures. Inèdit., 12 pàgines. Manresa

MATA-PERELLÓ. J.M. (1997).- Recerca geològica i mineralògica per les comarques de la Terra Alta i del Matarranya: des de Gandesa a Bot i Horta de Sant Joan, i des de Vallde-roures a Fondespatlla. Inèdit, 17 pàg. Manresa

MATA-PERELLÓ. J.M. (2000a).- Recerca geològica i mineralògica per les comarques de la Terra Alta i de la Ribera de l'Ebre: des de Pinell de Brai i Prat de Compte a Gandesa i a Mora d’Ebre. Algeps, sèrie B, nº 171, 14 pàg. Manresa

MATA-PERELLÓ. J.M. (2000b).- Recerca geològica i mineralògica per les comarques de la Terra Alta i del Matarranya: des de Gandesa a Vall-de-roures i a Fondespatlla. Algeps, sèrie $B, \mathrm{n}^{\circ} 176,18$ pàg. Manresa

MATA-PERELLÓ. J.M. (2001a).- Recorregut de recerca geològica i mineralògica per les comarques de la Ribera d'Ebre i de la Terra Alta: des d'Ascó a Pinell de Brai, i des de Prat de Compte a Horta de Sant Joan, Inèdit, 18 pàg. Manresa

MATA-PERELLÓ. J.M. (2001b).- Recorregut de recerca geològica i mineralògica per les comarques de la Terra Alta i del Matarranya: des d'Horta de Sant Joan a Vall-de-roures i a Fontespatlla Inèdit, 18 pàg. Manresa

MATA-PERELLÓ, J.M. (2005).- Recorreguts per la comarca de la Terra Alta: des del Pinell de Brai, a Prat de Compte i a Horta de Sant Joan. Inèdit. 12pag. Manresa

MATA-PERELLÓ. J.M. i HERRERA SANCHO, J.A. (2001).- Recorregut de recerca geològica, mineralògica i naturalístiques pels Ports Inèdit, 18 pàg. Manresa

MATA-PERELLÓ, J.M. i MONTANÉ GARCÍA, P. (2006).- Recorregut geològic i mineralògic per la comarca de la Terra Alta: des de Gandesa a Prat de Compte, a Horta de Sant Joan i a Arnés. Inèdit, 12 pag. Manresa

MATA-PERELLÓ, J.M., MONTANÉ GARCÍA, P. i GAVALDÂ CARDONA, V (2006).- Recorregut geològic i mineralògic per la comarca de la Terra Alta: des de Gandesa a la Fontcalda, Prat de Compte, Horta de Sant Joan, Arnés i a Vall-de-roures. Inèdit, 14 pag. Manresa 
RIBA, O. et altri (1976).- Geografia Física dels Països Catalans, Edit. Ketres, 254 pàgines. Barcelona. 